\title{
Inflammatory Cytokine Release in Patients with Unstable Angina after Coronary Angioplasty
}

\author{
QI Xiaoyong, ${ }^{1} \mathrm{MD}$, PENG Yingxin, ${ }^{1} \mathrm{MD}$, Gu Jian, ${ }^{1} \mathrm{MD}$, Li Shuren, ${ }^{1} \mathrm{MD}$, \\ ZHENG Shiling, ${ }^{1}$ MD, ZHANG Jianqing, ${ }^{1} \mathrm{MD}$, and WANG Tianhong, ${ }^{1} \mathrm{MD}$
}

\begin{abstract}
SUMMARY
The aim of the present study was to investigate inflammatory cytokine release and the interaction with platelets in patients with unstable angina (UA) after coronary angioplasty.

In 50 patients with stable angina (SA) and 58 patients with UA, serial venous blood samples were obtained immediately before, and 30 minutes, 4, 12, 24, 48 and 72 hours, and 7 days after coronary angioplasty. Plasma concentrations of IL-8 and vWF were determined by immunoassay, while the expression of $\mathrm{CD} 11 \mathrm{~b} / \mathrm{CD} 18$ on monocytes and the expression of CD41 on platelets were assessed by flow cytometry.

Differences in the baseline plasma concentrations of IL-8, vWF and CD11b/CD18, CD41 were found in the UA and SA groups before angioplasty $(101.1 \pm 31.28 \mathrm{pg} / \mathrm{mL}$ to $55.8 \pm 17.24 \mathrm{pg} / \mathrm{mL}, \quad 137.67 \pm 38.14 \%$ to $107.40 \pm 28.67 \%$ and $318.67 \pm 36.85$ MFI to $240.72 \pm 28.43$ MFI, $147.5 \pm 23.18$ MFI to $104.43 \pm 26.68$ MFI all $p<0.05)$. The peak plasma levels of IL-8 (172.24 $\pm 37.82 \mathrm{pg} / \mathrm{mL}$ at 12 hours) and vWF (256 $\pm 42.32 \%$ at 4 hours) significantly increased after coronary angioplasty (both $p<0.01$ ), and were associated with significant time course increases in surface expression of CD11b/CD18 $(p<0.01)$ and CD41 $(p<0.01)$. The levels of plasma IL-8 and vWF were significantly higher pre- and post-procedure in UA patients with lesion type $\mathrm{C}$ compared to types $\mathrm{A}$ or $\mathrm{B}(p<0.05)$, but there were no differences for pre-procedure in the SA group patients with different lesion types $(p>0.05)$. There were significant correlations between plasma IL- 8 and monocyte $\mathrm{CD} 11 \mathrm{~b} / \mathrm{CD} 18$, vWF and CD41 in the UA group $(r=0.5248, r=0.6240$ both $p<0.01$, respectively).

The findings demonstrate increases in plasma IL- 8 and CD11b/CD18 as inflammatory mediators, vWF and CD41 as the abnormal coagulation activity may therefore yield a rationale for pharmacological anticytokines in patients with UA after coronary angioplasty. (Jpn Heart J 2002; 43: 103-115)
\end{abstract}

Key words: Coronary angioplasty, IL-8, CD11b/CD18, CD41, vWF

Percutaneous coronary angioplasty is an established myocardial revascularization procedure. However, the high initial success rate is limited by the restenosis rate which ranges from $30 \%$ to $60 \%{ }^{1)}$ and the risk of acute complications

From ${ }^{1}$ Cardiac Center, Hebei Provincial People's Hospital of Hebei Medical University, Shijiazhuang, China.

Address for correspondence: Qi Xiaoyong, MD, Cardiac Center, Hebei Provincial People's Hospital of Hebei Medical University, 348 Hepingxi Road, Shijiazhuang 0570071, China.

Received for publication July 26, 2001.

Revised and accepted November 15, 2001. 
which ranges from $5 \%$ to $30 \%$ in unstable patients. ${ }^{2,3)}$ Inflammatory responses and platelet activation are considered to be the primary causes of inverse events after coronary angioplasty. This possibility is supported by experimental and clinical studies showing that acute phase reactants and proinflammatory cytokines promote leukocyte, endothelial and smooth muscle cell activation, resulting in an increase in procoagulant activity. ${ }^{4}$ Some therapeutic strategies designed to reduce the inflammatory interactions of leukocytes and endothelial cells have resulted in beneficial effects. ${ }^{5-10)}$

Interleukin-8 (IL-8), a CXC chemokine that induces the migration and proliferation of endothelial and smooth muscle cells, is an important activator and chemoattractant for neutrophiles. ${ }^{11)}$ Koch and Strieter ${ }^{12,13)}$ previously found that IL-8 had endothelial cell chemotactic activity in vitro and induced neovascularization in the cornea of rats and rabbits in vivo. Recently, it has been reported that IL-8 may contribute to plaque formation via its angiogenic properties in human coronary atherosclerosis. ${ }^{14)}$ Therefore, we select IL-8 as an inflammatory cytokine with which to investigate the cardiac inflammatory responses and interaction with platelets and further examination of Von Willebrand factor (vWF), the expression of $\beta_{2}$-integrin Mac-1 (CD11b/CD18) on monocytes and the expression of GPIIb/IIIa (CD41) on platelets in patients undergoing coronary angioplasty.

\section{METHODS}

Patients: The study group consisted of 108 consecutive patients who underwent coronary angioplasty on a single coronary stenosis; 50 patients with stable angina and 58 patients with unstable angina. An indication for coronary angioplasty was based on a history of postinfarction angina and/or a positive exercise stress test in the presence of a significant $(>75 \%)$ residual stenosis. Exclusion criteria were: myocardial infarction (MI) within three months, multilesion coronary angioplasty, total occlusion, previous or bypass surgery, a left ventricular ejection fraction $<30 \%$, left bundle branch block, and patients with interfering noncardiac diseases such as inflammatory disorders, malignancy, or infection. The regular medications of the patients were not altered for the study. None of the patients was on any anti-inflammatory agent except aspirin $150 \mathrm{mg} / \mathrm{dL}$. Twenty angiographically normal patients served as controls. The Hospital Ethics Committee for Human Subjects approved the study. Written informed consent was obtained from all patients.

Blood sampling: Peripheral blood samples were taken immediately before and 30 minutes, 4, 12, 24, 48, and 72 hours, and 7 days after balloon angioplasty. Coded plasma samples were stored at $-80^{\circ} \mathrm{C}$ and analyzed in a single batch at the 
end of the study, and thus, patient management was independent of these results. In the 20 angiographically normal patients, only pre-angioplasty blood samples were obtained. Laboratory assays: IL- 8 and vWF were assayed by an automated monoclonal antibody solid phase sandwich-type enzyme immunoassay (Abbott 311S, Abbott Laboratories, North Chicago, Illinois).

Flow cytometry: Results are expressed as the mean fluorescence intensity (MFI). The blood samples for flow cytometry were treated with anticoagulant [1:5 (vol/vol) CPDA (sodium citrate, phosphate buffer, dextrose, adenine; Fa Greiner)]. Staining was performed in whole blood with fluorescein-isothiocyanate (FITC)-conjugated anti-CD11b/CD18 complex and CD41 (clone, Bear1, Immunities). Whole blood ( $25 \mu \mathrm{L})$ and an equal volume of PBS were incubated with saturating concentrations of FITC-conjugated MAbs for 30 minutes at room temperature. Erythrocytes were lysed and leukocytes were fixed with commercially available solutions (lysing solution and fixing reagent, Coulter Electronics). The cells were then washed three times and stored in $1 \%$ para formaldehyde at $4^{\circ} \mathrm{C}$ until flow cytometry analysis was performed within 24 hours after sampling. MAb binding was assessed by flow cytometry with a FACS Vantage (Becton-Dickinson) equipped with a 488-nm argon laser at $500 \mathrm{~mW}$. Reproducibility was ensured by calibration with a mixture of fluorescent monosized beads. To analyze the monocytes, a gate was set in the forward angle versus right angle scatter. The fluorescence intensity of 10,000 events was recorded as the mean channel number over a logarithmic scale of 1 to 1026 channels. Data were stored in list mode files and processed on a Hewlett Packard computer programmed with Cell Quest software.

Coronary angioplasty: Coronary angiography was performed with Judkins catheters via the right femoral artery using a digital angiographic system. Angiography, coronary angioplasty, and stent implantation (BX, Cordis; AVE, Medtronic) were performed by experienced investigators only. All patients received heparin at the dose required to maintain the activated clotting time above 300 seconds throughout the procedure. Catheter-related parameters were determined as shown in Table I.

Qualitative and quantitative assessment: Two expert angiographers who were unaware of the patients' clinical and analytic data independently reviewed an enddiastolic frame of the vessel segment. To standardize the method of data acquisition and to ensure exact reproducibility of the angiographic studies, the coronary angiograms were recorded in such a manner that they were suitable for QCA by the computer-assisted Coronary Angiography Analysis System, which has been described and validated. ${ }^{15)}$ Angiographic lesion morphology before coronary angioplasty was categorized as three types (A, B, and C) according to the American College of Cardiology/American Heart Association Task Force classifica- 
tion. ${ }^{16)}$ Minimal luminal diameter, percent of diameter stenosis, acute gain, and balloon/vessel ratios were assessed by computerized quantitative angiography. Procedural angiograms were also analyzed for Thrombolysis in Myocardial Infarction (TIMI) flow grade. ${ }^{17)}$ Coronary angioplasty was considered successful if the final percent diameter stenosis was less than $30 \%$ with a TIMI 3 flow in the absence of death, recurrent ischemia, MI (creatine kinase increase to more than two times the upper limit of normal with or without evidence of new Q waves), or if the patient needed urgent coronary bypass graft surgery (CABG) during the hospital period.

Statistical analysis. Statistical analysis was performed using the Statistical Package for Social Sciences software (SPSS 10.0 for Windows, SPSS Inc, Illinois). A $p$ value $<0.05$ was considered statistically significant.

\section{RESUltS}

Baseline characteristics: Clinical characteristics, angiographic findings, and procedural variables are summarized in Table I. Before coronary angioplasty, the

Table I. Baseline Characteristics of Clinical, Angiographic and Procedural Parameters

\begin{tabular}{llll}
\hline & $\begin{array}{l}\text { Stable group } \\
(\mathrm{n}=50)\end{array}$ & $\begin{array}{l}\text { Unstable group } \\
(\mathrm{n}=58)\end{array}$ & $P$ \\
\hline Age & $63.7 \pm 8.2$ & $62.6 \pm 8.1$ & 0.468 \\
Male (M/F) & $38 / 12$ & $44 / 14$ & 0.987 \\
Systemic hypertension, $\mathrm{n}(\%)$ & $23(46)$ & $27(47)$ & 0.954 \\
Diabetes mellitus, $\mathrm{n}(\%)$ & $14(28)$ & $17(29)$ & 0.881 \\
Cigarette smoking, $\mathrm{n}(\%)$ & $32(64)$ & $38(66)$ & 0.869 \\
Prior MI & $14(28)$ & $16(31)$ & 0.962 \\
Body mass index & $24.54 \pm 3.34$ & $24.29 \pm 3.15$ & 0.693 \\
Cholesterol (mg/dL) & $222.4 \pm 27.2$ & $219.7 \pm 28.2$ & 0.604 \\
Triglycerides (mg/dL) & $139.6 \pm 18.5$ & $133.2 \pm 24.1$ & 0.266 \\
Dilated coronary artery & & & \\
Left anterior descending, $\mathrm{n}(\%)$ & $34(68)$ & $38(66)$ & 0.785 \\
Left circumflex, $\mathrm{n}(\%)$ & $6(12)$ & $8(14)$ & 0.782 \\
Right coronary artery, $\mathrm{n}(\%)$ & $10(20)$ & $12(20)$ & 0.929 \\
A/B/C lesion type* & $20 / 19 / 11$ & $23 / 21 / 14$ & 0.867 \\
Percent diameter, \% & $79 \pm 13$ & $78 \pm 14$ & 0.632 \\
Minimal lumen diameter, mm & $0.40 \pm 0.15$ & $0.38 \pm 0.21$ & 0.640 \\
Small vessel (<3.0 mm), $\mathrm{n}(\%)$ & $23(46)$ & $28(48)$ & 0.813 \\
Multivessel disease, $\mathrm{n}(\%)$ & $34(68)$ & $39(67)$ & 0.933 \\
Inflation pressure atm & $6.7 \pm 1.7$ & $6.6 \pm 1.7$ & 0.815 \\
Total inflation time, s & $90 \pm 12$ & $92 \pm 28$ & 0.588 \\
Balloon vessel ratio & $1.0 \pm 0.2$ & $1.0 \pm 0.2$ & 0.956 \\
Acute gian, mm & $1.83 \pm 0.25$ & $1.82 \pm 0.29$ & 0.843 \\
Target stenosis after PTCA & & & 0.236 \\
Percent diameter, \% & $30 \pm 3$ & $31 \pm 3$ & 0.544 \\
Minimal lumen diameter, mm & $2.21 \pm 0.14$ & $2.19 \pm 0.12$ & \\
\hline
\end{tabular}

* $\mathrm{ACC} / \mathrm{AHA}^{(20)} \mathrm{MI}=$ myocardial infarction. 
plasma concentrations of IL-8 and vWF were higher in the UA group than in the SA group and normal controls (both $p<0.05$ ), but there was no difference between the latter two groups (both $\mathrm{p}>0.05$ ). Increases in CD11b/CD18 and CD41 were observed in the UA group (both $p<0.05$, Table II). The levels of plasma IL- 8 and vWF in UA patients with complex lesions (type C) before coronary angioplasty were significantly higher than those with types A or B (Figures 1 and $2 ; p<0.05$, respectively).

Table II. Baseline Levels of IL-8, vWF and CD11b/CD18 (mean+SEM)

\begin{tabular}{llll}
\hline & $\begin{array}{c}\text { Normal control } \\
(\mathrm{N}=20)\end{array}$ & $\begin{array}{c}\text { Stable Angina } \\
(n=50)\end{array}$ & $\begin{array}{c}\text { Unstable Angina } \\
(n=58)\end{array}$ \\
\hline IL-8, pg/mL & $44.32 \pm 12.68$ & $55.8 \pm 17.24^{\Delta}$ & $101.1 \pm 31.28^{* *}$ \\
vWF (\%) & $89.67 \pm 21.87$ & $107.40 \pm 28.67^{\Delta}$ & $137.67 \pm 38.14^{* *}$ \\
CD11b/CD18, MFI & $223.50 \pm 24.21$ & $240.72 \pm 28.43^{\Delta}$ & $318.67 \pm 36.85^{* *}$ \\
CD41, MFI & $89.50 \pm 19.45$ & $104.43 \pm 26.68^{\Delta}$ & $147.5 \pm 23.18^{* *}$ \\
\hline
\end{tabular}

${ }^{\Delta}$ compared with normal control $P>0.05, * *$ compared with SA $P<0.05$.

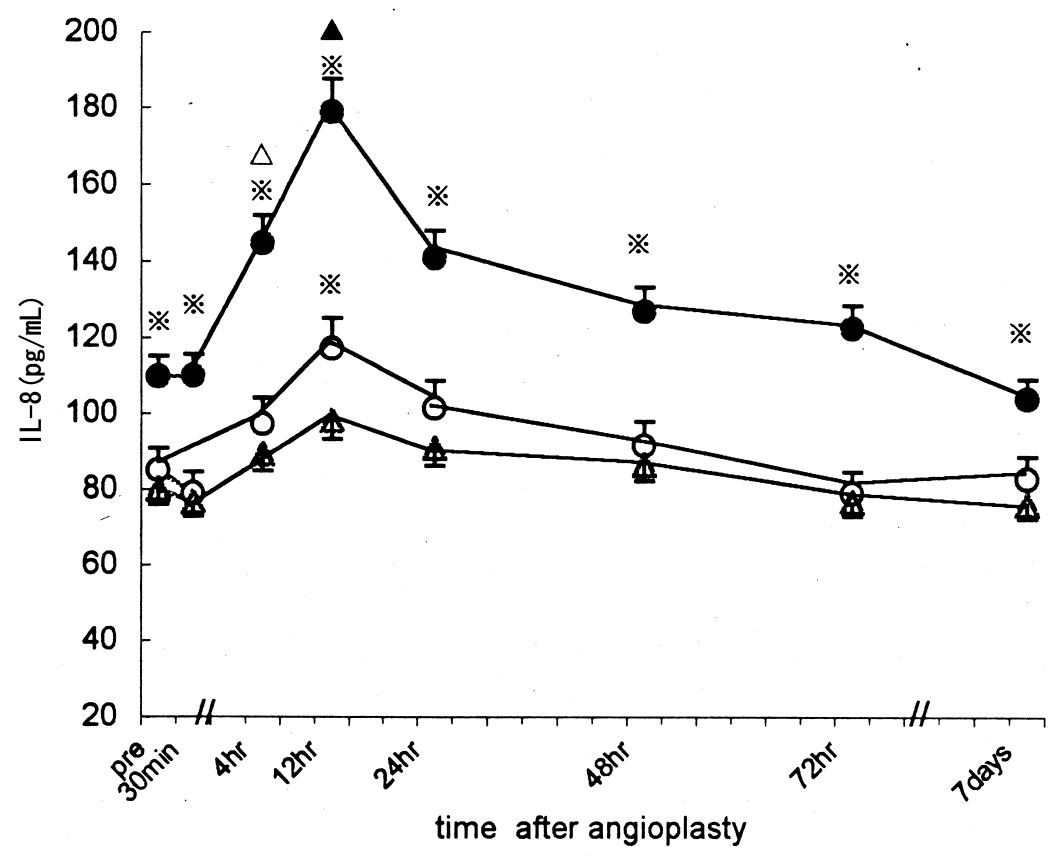

Figure 1. Serial changes in plasma IL-8 after PTCA in UA patients with lesion types A $(\Delta), \mathrm{B}(\bigcirc)$ and $\mathrm{C}(\boldsymbol{\bullet})$ according to the ACC/AHA guidelines. *indicates significant $(p<0.05)$ differences between $\mathrm{C}$ and B or A groups. $\Delta p<0.05, \mathbf{\Lambda} p<0.01$ compared with values before PTCA. 
After coronary angioplasty, plasma IL-8 in the UA group increased from $141.11 \pm 21.43 \mathrm{pg} / \mathrm{mL}$ at 4 hours $(p<0.05)$ to a peak level of $172.24 \pm 37.82 \mathrm{pg} / \mathrm{mL}$ at 12 hours $(p<0.01)$, and then tended to decrease to normal levels within 24 hours. Even though vWF increased from $207.23 \pm 38.78 \%$ at 30 minates $(p<0.05)$ to a peak of level $256.24 \pm 42.32 \%$ at 4 hours $(p<0.01)$ and remained elevated for 7 days, the changes were not as significant as those in the SA group (Figure 3).

In the UA group after coronary angioplasty, CD11b/CD18 significantly increased from $398.21 \pm 53.14(\mathrm{MFI})$ at 12 hours $(p<0.05)$ to a peak level of $455.67 \pm 68.21(\mathrm{MFI})$ at 24 hours $(p<0.01)$, and the changes lasted for 7 days. These changes were not seen in the SA group (Figure 4). The changes in transcardiac gradient in the UA group were significantly correlated with the peak plasma IL-8 (Figure 5; $r=0.5248 p<0.01$ ). Platelet CD41 exhibited the same trend as $\mathrm{CD} 11 \mathrm{~b} / \mathrm{CD} 18$ and had a significant correlation with peak plasma vWF (Figure 6; $r=0.6240 ; p<0.01)$. However, there was no significant correlation between the peak levels of plasma IL-8 and vWF $(r=0.0035 ; p>0.05)$.

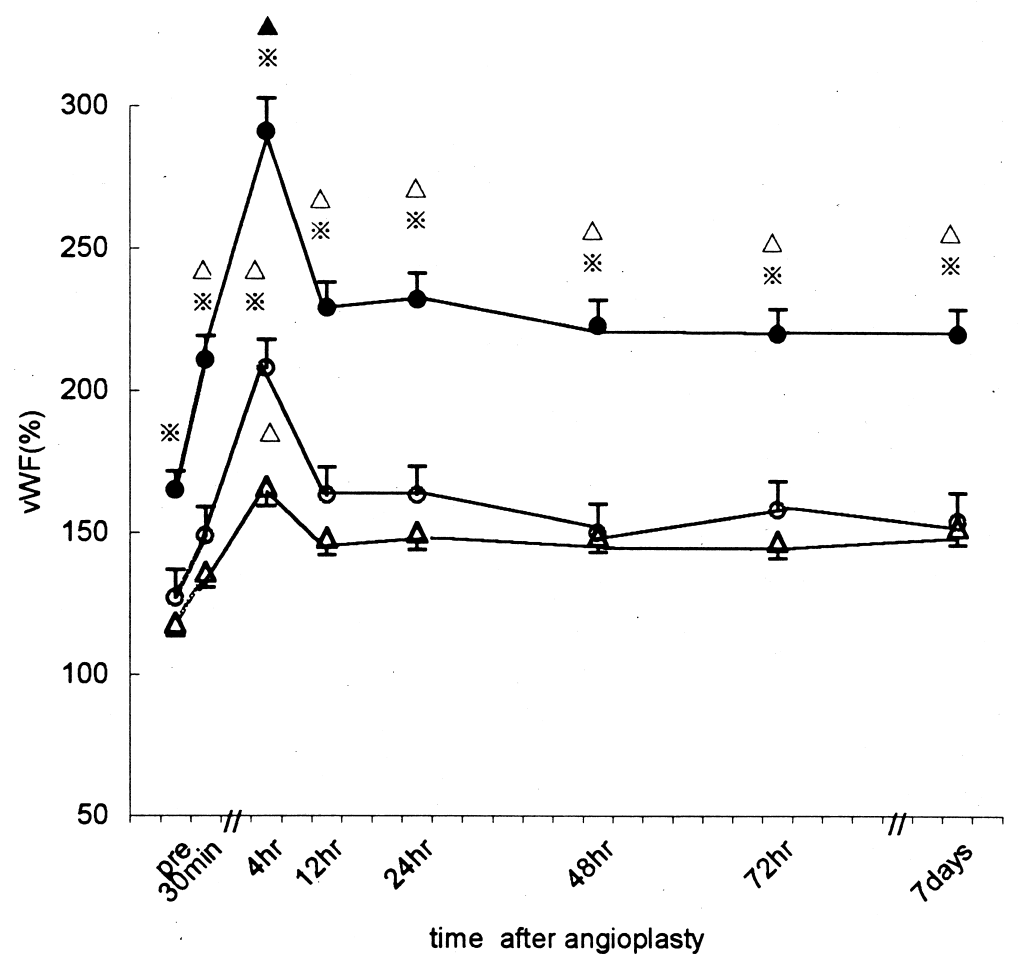

Figure 2. Serial changes in plasma levels of vWF after PTCA in UA patients with lesion types A $(\Delta), \mathrm{B}(\mathrm{O})$ and $\mathrm{C}(\bullet)$ according to the ACC/AHA guidelines. *indicates significant $(p<0.05)$ differences between $\mathrm{C}$ and $\mathrm{B}$ or A groups. $\Delta P<0.05, \boldsymbol{\Delta} p<0.01$ compared with values before PTCA. 


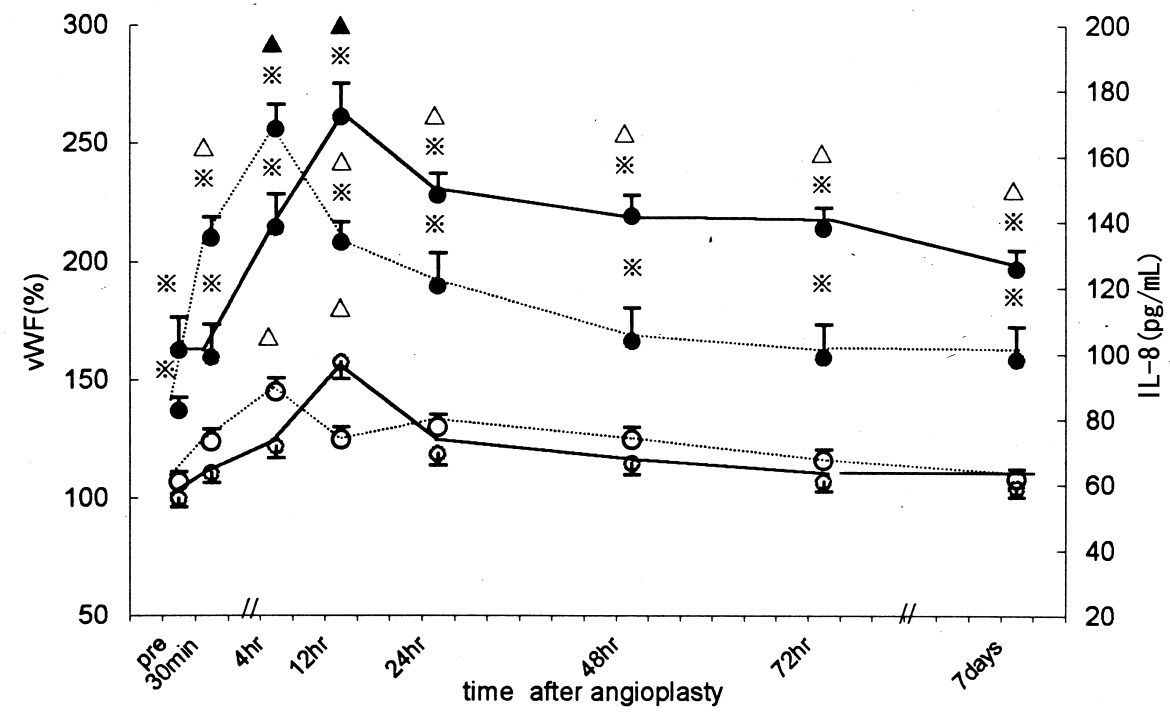

Figure 3. Serial changes in plasma levels of vWF (dashed lines) and IL-8 (solid lines) after PTCA in patients with UA (๑) and SA (O). *indicates significant $(p<0.05)$ differences between both groups. $\Delta p<0.05, \mathbf{\Delta} p<0.01$ compared with values before PTCA.

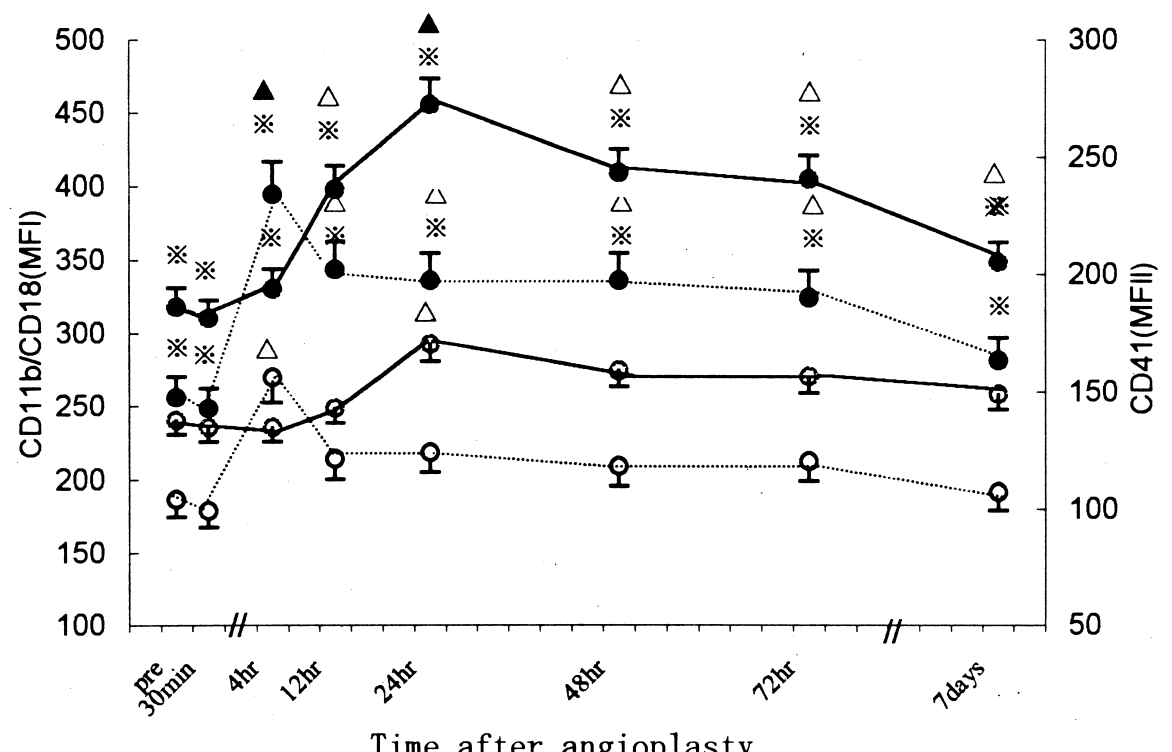

Figure 4. Serial changes in monocyte surface expression CD11b/CD18 (solid lines) and CD41 (dashed lines) after PTCA in patients with UA $(\bullet)$ and SA (O). *indicates significant $(p<0.05)$ differences between both groups. $\Delta p<0.05, \Delta p<0.05$ compared with values before PTCA. 


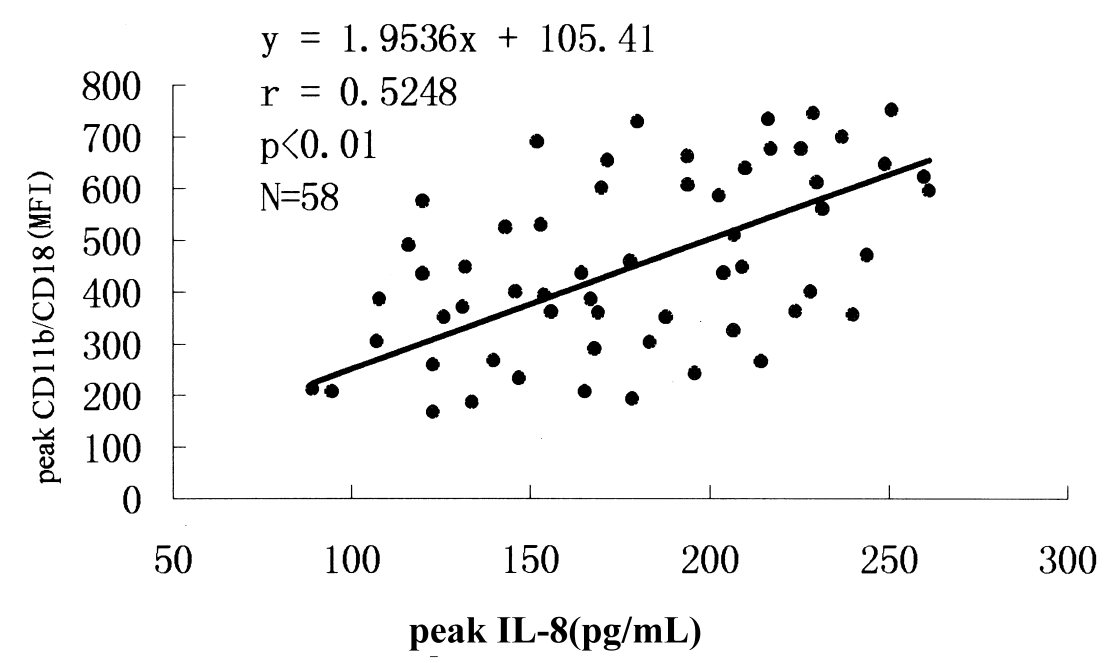

Figure 5. Scattergraph showing peak IL- 8 concentrations in plasma on the $X$ axis and peak CD11b/CD18 on the $\mathrm{Y}$ axis in UA group.

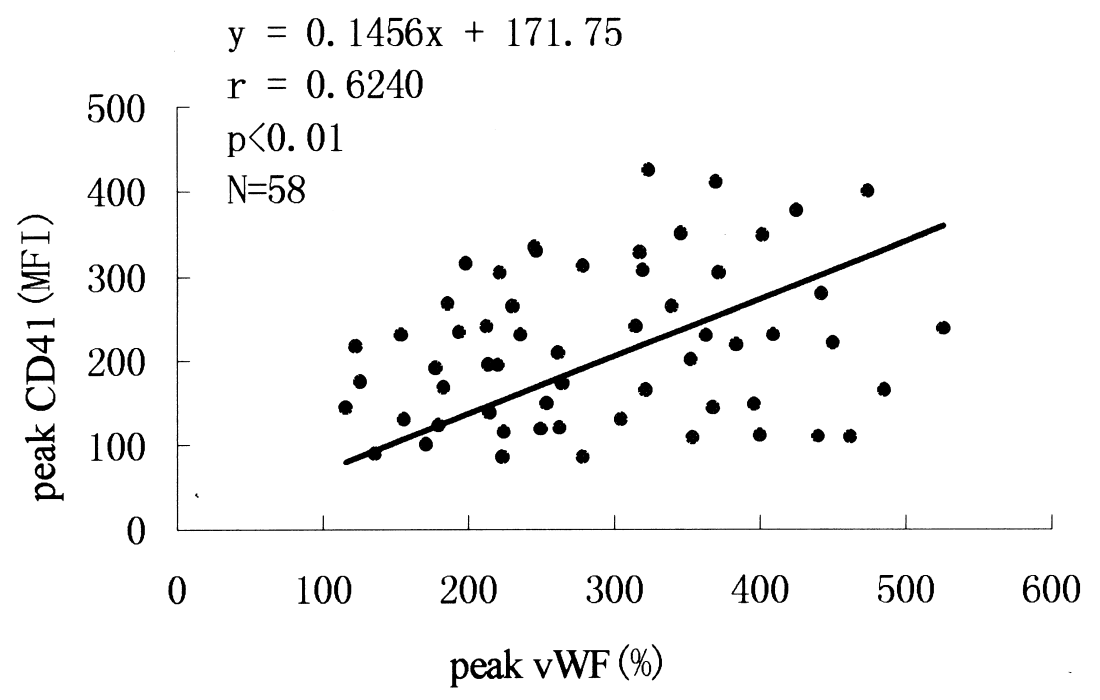

Figure 6. Scattergraph showing peak vWF-8 concentrations in plasma on the $\mathrm{X}$ axis and peak CD41 on the $\mathrm{Y}$ axis in UA group. 


\section{DISCUSSION}

This report summarizes a clinical study that reveals plasma cytokine release after coronary angioplasty in patients with angina. The main findings are (1) a release of plasma IL-8, (2) monocyte activation evidenced by increased surface expression of CD11b/CD18, (3) platelet-monocyte conjugates demonstrated by elevated expression on platelet CD41, and (4) endothelial injury and coagulation activity manifested by an increase in vWF.

The inflammatory responses and cardiac release of cytokines after infarctrelated LAD occlusion recanalized by coronary angioplasty in AMI have been reported. ${ }^{18)}$ The cardiac inflammatory responses in acute MI arise largely from the reperfused area. ${ }^{19)}$ Most of the changes can be demonstrated only after reperfusion has been established. However, all the transcardiac factors reflecting inflammatory responses increased substantially pre- and post-angioplasty in this study.

It has previously been reported that IL- 8 is an important activator and chemoattractant for neutrophiles. Recently, it was further shown that the increased plasma IL- 8 in patients with unstable angina pectoris may play a key role as a marker of ischemic events. ${ }^{20-22)}$ This study demonstrates a time course increase in plasma IL-8 in unstable angina that extends to 7 days after coronary angioplasty. The transcardiac differences in IL-8 concentrations showed a remarkable increase in the UA group pre-and post-angioplasty. A sizable increase in plasma IL-8, however, occurs after angioplasty of the stenosis vessel even in patients with stable angina who had a normal level of plasma IL-8 before coronary angioplasty. The increase in plasma IL- 8 before angioplasty may be attributed to residual perfusion of the ischemia area, but may be due to the stability of lesions, as evidenced by the levels of plasma IL-8 and vWF, both of which were significantly higher in the UA group than in the SA group. ${ }^{21,23)}$ Furthermore, ischemic preconditioning results in no effect on systemic inflammatory cytokine release of IL- 8 in the early stages after coronary artery bypass surgery. ${ }^{24)}$

In addition, there were significant differences in IL- 8 between lesion type $\mathrm{C}$ and types A or B pre- and post- angioplasty in UA patients. This may be related to the instability of lesions, as there were no differences between the different lesion types in SA patients. Moreover, the lesion type mainly represent the complexity of coronary artery atherosclerosis depending the lesion vessels on morphology of lesion, severity of stenosis and calcium, elevated level of IL-8 in type $\mathrm{C}$ lesion may rather involved in the coronary atherosclerotic plaques than the lesion type itself. The expression of IL- 8 protein and mRNA has been reported in the plaque macrophages and circulating monocytes of patients presenting with clinically significant atheromas, ${ }^{23)}$ as well as in their macrophages and foam cells in response to cholesterol loading. ${ }^{25,26)}$ Other investigators have separately dem- 
onstrated the presence of the IL- 8 protein and evidence of neovascularization in atherosclerotic plaques. ${ }^{12,27)}$ The different plasma levels of IL- 8 in three types of angiographic lesion may hint at an important relationship between IL- 8 and coronary artery atheromas.

The findings of the current study agree with the above observations. The colocalization of IL- 8 with factor vWF supports a role for IL- 8 as a contributor to endothelial cell impairment and recruitment in human coronary plaques. This evidence would therefore support a mechanism by which IL-8 is, at least partially, a mediator of the angiogenesis associated with atherosclerosis and elucidate potential mechanisms by which IL-8, a new inflammatory cytokine only recently described in human atherosclerosis, may contribute to the development and progression of coronary atherosclerotic disease in humans. Although we do not provide direct evidence, we speculate that the vascular endothelium may be another predominant source of the cardiac release of IL-8. Endothelial cells have been shown to produce IL- 8 on stimulation with a variety of inflammatory mediators. Cultured endothelial cells release IL-8 under hypoxic conditions, ${ }^{28)}$ however, the ischemia itself may not be the only adequate stimulus for the release of IL-8 because there were different levels of plasma IL-8 between stable and unstable groups before coronary angioplasty, and therefore the detectable transcardiac gradients in plasma IL-8 demonstrated the release of injured endothelium cells after coronary angioplasty. Accordingly, we hypothesized that the local inflammatory actions of IL-8 may induce changes in surface receptor expression on monocytes. Consistent with this concept, we found increased surface expression on monocytes of CD11b/CD18 and a good correlation with the time course of plasma IL8 following angioplasty. These findings indicate that the reperfused coronary circulation before coronary angioplasty represents a proinflammatory environment, and furthermore, stimulated activation after coronary angioplasty, which may further damage the vascular endothelium, as evidenced by the parallel elevation of vWF.

VWF is an established marker for endothelial injury, as proved in various clinical studies, such as the collar model. ${ }^{29)}$ In cell culture studies it has been demonstrated that endothelial cells (ECs) can be stimulated to release additional large amounts of vWF under conditions of stress (eg, hemodynamic changes), ${ }^{30)}$ and also the release of vWF mediated by inflammatory stimuli. ${ }^{31-36)}$ This study demonstrates that increased plasma levels of vWF and a significant correlation with peak express level of platelet CD41 reflect endothelial injure and may be indicating poor prognosis of cardiovascular events for the stimulated abnormal activity of coagulation system. ${ }^{37-41)}$ The ESSENCE Trial reported that the early rise in vWF is an independent predictor of adverse clinical outcome in a one-year follow up in unstable angina patients. ${ }^{42,43)}$ The increased synthesis and release of vWF in 
atherosclerotic plaques and intimal thickenings may be important to early complications and late restenosis after coronary angioplasty. Increased synthesis and release of vWF by itself may stimulate intimal thickening and plaque formation, but vWF appeared to be non-essential for shear-induced smooth muscle cell accumulation in the intima. Therefore, the vWF seems not to be important for the formation and development of arteriosclerosis since it was demonstrated there were no differences between different lesion types in the SA group. However, vWF could play a role in the stability of atherogenesis. It is conceivable that the increased production of VWF in the UA group was significantly higher than that in the SA group. Furthermore, there were significant differences between lesion type $\mathrm{C}$ and types $\mathrm{A}$ or $\mathrm{B}$ in the UA group. On the other hand, it is well known that vWF is important in platelet-vessel wall interactions and that it has prohemostatic properties. The present study has demonstrated that the increased amounts of vWF on the ECs of atherosclerotic aortas resulted in an increased adhesion of platelets to the vessel wall. ${ }^{30)}$ This may have important clinical consequences, eg, during plaque rupture when vWF deposits in the plaque become exposed to blood, enhancing the development of thrombosis, and further progressing a platelet-fibrin microthrombus to an occlusive thrombus. However, the results of the present study suggest that nominal anticoagulant treatment can not provide the same protection with regards to vWF release. ${ }^{44)}$ AJvW-2, an anti-vWF monoclonal antibody that can block the interaction between plasma vWF and platelet glycoprotein, may prevent further events in the coronary arteries. ${ }^{45}$

One limitation of our study is the relatively small number of patients divided into the subgroup with different lesion types. Among potential inflammatory mediators after coronary angioplasty, this study investigated only the cytokines IL-8 and vWF, and CD11b/CD18 and CD41. A number of additional mediators, such as IL-1, IL-6, and CRP, however, may contribute to the cardiac inflammatory responses following coronary angioplasty. Furthermore, the specificity of the factors and their roles in early complications and late restenosis need to be studied further.

Moreover, the systemic inflammatory response syndrome may increase the short-term risk of early complications and long-term restenosis. The identification of IL-8 and CD11b/CD18 as inflammatory mediators, and VWF and CD41 as indicating abnormal coagulation activity in patients with unstable angina may therefore yield a rationale for pharmacological anti-inflammatory responses and interactions with platelets after coronary angioplasty. 


\section{REFERENCES}

1. Popma JJ, Califf RM, Topol EJ. Clinical trials of restenosis after coronary angioplasty. Circulation 1991; 84: 1426-36.

2. Lincoff AM, Popma JJ, Ellis SG, Hacker JA, Topol EJ. Abrupt vessel closure complicating coronary angioplasty: clinical, angiographic and therapeutic profile. J Am Coll Cardiol 1992; 19: 926-35.

3. de Feyer PJ, Ruygrok PN. Coronary intervention: risk stratification and management of abrupt coronary occlusion. Eur Heart J 1995; 16 Suppl L: L97-103.

4. Oliver JC, Bland LA, Oettinger CW, et al. Cytokine kinetics in an in vitro whole blood model following an endotoxin challenge. Lymphokine Cytokine Res. 1993; 12: 115-20.

5. Thompson RC, Holmes DR, Jr, Cersh BJ, Bailey K. Predicting early and intermediate-term outcome of coronary angioplasty in the elderly. Circulation 1993; 88: 1579-87.

6. Ellis SG, Vandormael MG, Cowley MJ, et al. Coronary morphologic and clinical determinants of procedural outcome with angioplasty for multivessel coronary disease. Implications for patient selection. Circulation 1990; 82: 1193-202.

7. Tan K, Sulke N, Taub N, Sowton E. Clinical and lesion morphologic determinants of coronary angioplasty success and complications: current experience. J Am Coll Cardiol 1995; 25: 855-65.

8. Oltrona L, Eisenberg PR, Lasala JM, Sewall DJ, Shelton ME, Winters KJ. Association of heparin-resistant thrombin activity with acute ischemic complications of coronary interventions. Circulation 1996; 94: 2064-71.

9. Tschoepe D, Schultheib HB, Kolarrov P, et al. Platelet membrane activation markers are predictive for increased risk of acute ischemic events after PTCA. Circulation 1993; 88: 37-42.

10. Rensing BJ, Heramns WRM, Vos J, et al. Lemind narrowing after percutaneous coronary angioplasty: a study of clinical, procedural and lesional factors related to long-term angiographic outcome. Circulation 1993; 88: 975-85.

11. Roebuck KA. Regulation of interleukin-8 gene expression. Interferon Cytokine Res. 1999; 19: 429-38.

12. Koch AE, Polverini PJ, Kunkel SL. Interleukin-8 (IL-8) as a macrophage-derived mediator of angiogenesis. Science 1992; 258: 1798-801.

13. Strieter RM, Kunkel SL, Elner VM, et al. Interleukin-8 a corneal factor that induces neovascularization. AM J Pathol. 1992; 141: 1279-1284.18.

14. Simonini A, Moscucci M, Muller DW, et al. IL-8 is an angiogenic factor in human coronary atherectomy tissue. Circulation 2000; 101: 1519-26.

15. Serruys PW, Foley DP, deFeyter PJ, Eds. Quantitative Coronary Angiography in Clinical Practice. Dordrecht, Netherlands: Kluwer Academic Press. 1994.

16. yan TJ, Faxon DP, Gunnar RM, et al. Guidelines for percutaneous transluminal coronary angioplasty. A report of the American College of Cardiology/American Heart Association Task Force on Assessment of Diagnostic and Therapeutic Cardiovascular Procedures (Subcommittee on Percutaneous Transluminal Coronary Angioplasty). Circulation 1988; 78: 486-502.

17. The TIMI Study Group. The Thrombolysis in Myocardial Infarction (TIMI) trial. N Engl J Med 1985; 312 : 932-6.

18. Neumann FJ, Ott I, Wilhelm H, Katus H, Tillmanns H, Schomig A. Release of chemoattractants and neutrophile activation in acute myocardial infarction immediately after successful recanalization of the infarct-related vessel by angioplasty. Eur Heart J 1994; 15: 171-8.

19. Neumann FJ, Ott I, Meinrad Gawaz, et al. Cardiac release of cytokines and inflammatory responses in acute myocardial infarction. Circulation 1995; 92: 748-55.

20. Aukrust P, Berge RK, Ueland T, et al. Interaction between chemokines and oxidative stress: possible pathogenic role in acute coronary syndromes. J Am Coll Cardiol 2001; 37: 485-91.

21. Simiti A, Vida-simiti L, Cristea A, Olinic N. Increased plasma levels of interleukin-8 in patients with unstable angina pectoris. Rom J Intern Med 1998; 36: 47-56.

22. Kanda T, Hirao Y, Oshima S, et al. Interleukin-8 as a sensitive marker of unstable coronary artery disease. Am J Cardiol 1996; 77: 304-7.

23. Ishibashi T, Kijima M, Yokoyama K, et al. Expression of cytokine and adhesion molecule mRNA in atherectomy specimens from patients with coronary artery disease. Jpn Circ J 1999; 63: 249-54. 
24. Wei M, Kunkasjarvi P, Laurikka J, Pehkonen E, Kaukinen S, Tarkka M. Cytokine responses in patients undergoing coronary artery bypass surgery after ischemic preconditioning. Scand Cardiovasc J 2001; 35: 141-6.

25. Wang N,Tabas I, Winchester R, Ravalli S, Rabbani L, Tall A. Interleukin-8 is induced by cholesterol loading of macrophages and expressed by macrophage foam cells in human atheromas. J Biol Chem 1996; 271: 8837-42.

26. Apostolopoulos J, Davenport P, Tipping P. Interleukin-8 production by macrophages from atherosclerotic plaques. Arterioscler Thromb Vasc Biol 1996; 16: 1007-12.

27. Kwon HM, Sanggiorgi G, Ritman EL, et al. Enhanced coronary vasa vasorum neovascularization in experimental hypercholestrolemia. J Clin Invest 1998; 1012: 1551-6.

28. Montalescot G, Ankri A,Vicaut E, Drobinski G, Crosgogeat Y, Thomas D. Fibrinogen after coronary angioplasty as a risk factor for restenosis. Circulation 1995; 92: 31-8.

29. Lip GY, Blann A. von Willebrand factor: a marker of endothelial dysfunction in vascular disorders? Cardiovasc Res. 1997; 34: 255-65.

30. De Meyer GR, HoyLaerts MF, Kockx MM, et al. Intimal deposition of functional von Willebrand factor in atherogenesis. Arteriosclerosis, Thrombosis, and Vascular Biology 1999; 19: 2524-34.

31. Ceponis A, Konttinen YT, MacKevicius Z, et al. Aberrant vascularity and von Willebrand factor distribution in inflamed synovial membrane. J Rheumatol 1996; 23: 1880-6.

32. Schorer AE, Moldow CF, Rick ME. Interleukin 1 or endotoxin increases the release of von Willebrand factor from human endothelial cells. Br J Haematol 1987; 67: 193-7.

33. Giddings JC, Shall L. Enhanced release of von Willebrand factor by human endothelial cells in culture in the presence of phorbol myristate acetate and interleukin 1. Thromb Res. 1987; 47: 259-67.

34. Hakkert BC, Rentenaar JM, van Mourik JA. Monocytes enhance endothelial von Willebrand factor release and prostacyclin production with different kinetics and dependency on intercellular contact between these two cell types. Br J Haematol 1992; 80: 495-503.

35. de Groot PG, Verweij CL, Nawroth PP, de Boer HC, Stern DM, Sixma JJ. Interleukin-1 inhibits the synthesis of von Willebrand factor in endothelial cells, which results in a decreased reactivity of their matrix toward platelets. Arteriosclerosis 1987; 7: 605-11.

36. Breit SN, Green I. Modulation of endothelial cell synthesis of von Willebrand factor by mononuclear cell products. Haemostasis 1988; 18: 137-45.

37. Holvoet P, Donck J, Landeloos M, et al. Correlation between oxidized low density lipoproteins and von Willebrand factor in chronic renal failure. Thromb Haemost 1996; 76: 663-9.

38. Blann AD, Miller JP, McCollum CN. von Willebrand factor and soluble E-selectin in the prediction of cardiovascular disease progression in hyperlipidaemia. Atherosclerosis 1997; 132: 151-6.

39. Montalescot G, Philippe F, Ankri A, et al. for the French Investigators of the ESSENCE trial. Early increase of von Willebrand factor predicts adverse outcome in unstable coronary artery disease. Beneficial effects of enoxaparin. Circulation 1998; 98: 294-9.

40. Mannucci PM. von Willebrand factor: a marker of endothelial damage? Arterioscler Thromb Vasc Biol 1998; 18: 1359-62.

41. Bosmans JM, Kockx MM, Vrints CJ, Bult H, De Meyer GR, Herman AG. Fibrin and von Willebrand factor accumulations are associated with intimal thickening after balloon angioplasty. Arterioscler Thromb Vasc Biol 1997; 17: 634-45.

42. Montaescot G, Philippe F, Ankri A, et al. Early increase of von Willebrand factor predicts adverse outcome in unstable coronary artery disease: Beneficial effects of enoxaparin. French Investigators of the ESSENCE Trial. Circulation 1999; 99: 1924-5.

43. Montaescot G, Collet JP, Choussat R, Ankri A, Thomas D. A rise of troponin and/or von Willebrand factor over the first $48 \mathrm{~h}$ is associated with a poor 1-year outcome in unstable angina patients. Int J Cardiol 2000; 72: 293-4.

44. Montaescot G, Collet JP, Lison L, et al. Effects of various anticoagulant treatments on von Willebrand factor release in unstable angina. J Am Coll Cardiol 2000; $36: 110-4$.

45. Eto K, Isshiki T, Yamamoto H, et al. AjvW-2 an anti-vWF monoclonal antibody, inhibits enhanced platelet aggregation induced by high shear stress in platelet-rich plasma from patients with acute coronary syndromes. Arterioscler Thromb Vasc Biol 1999; 19: 877-82. 